\title{
IMPORTANCE OF HEALTH ECONOMICS FOR HEALTH PROFESSIONALS IN NEPAL
}

\author{
Vice Chairman, Birat Medical College \& Teaching Hospital \\ Denis Karki, MBA, PGDHCM, M.SC HEPM (LSE) \\ https://orcid.org/0000-0002-3821-2848 \\ Birat Medical College \& Teaching Hospital, Tankisinuwari, Morang, Nepal
}

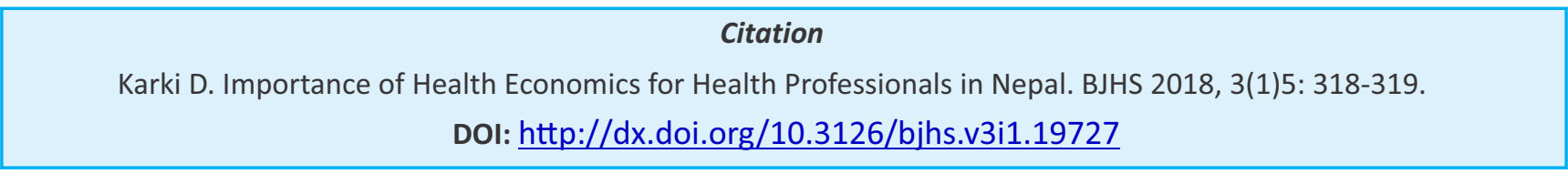

The demand for health care has been on the rise worldwide, and Nepal is no exception. With the growing population, aging demographic, demand for good health, changing lifestyles and improvements in technologies and interventions, Nepal is experiencing severe demand on its limited health resources. ${ }^{4}$ Going back just a few decades, the treatment choices for doctors were limited and patients did as they were told. Any values that contributed to the decision making process were implicit and determined by the doctors. However, the steady rise in demand has put a strain on resources that haven't itself undergone the same growth (Figure 1).

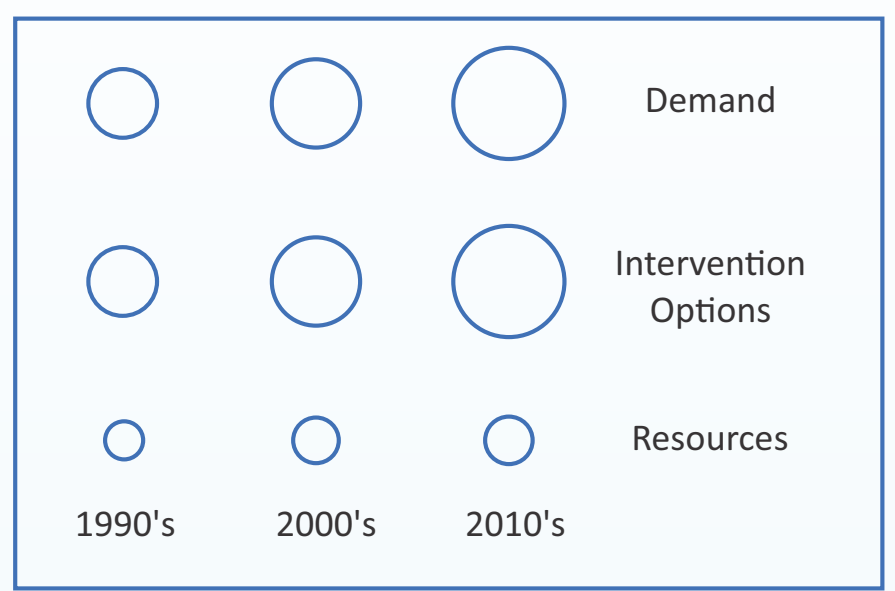

Figure 1: Diagrammatic representation of Nepal's increasing demand on limited resources with area of each circle reflecting size of each variable.

While overall access to healthcare for an average Nepali has seen significant improvement in the last three decades, sustainability of such performance will require urgent new development and innovative ways of working between public and private health sector in Nepal. ${ }^{1}$ The importance of economics is that it tries to provide insightful information into how health care can be financed and organised so that benefits from the available resources can be maximised.

Health care financing plays an important role in transforming the health care system of a country. The functions of health care financing-the collection of revenue, risk pooling and purchasing-are also critical for health policy designs. ${ }^{7}$ Nepalese health sector expenditure has been erratic to say the least. While the commitments of the government as a share of GDP reflect a steady growth, the trend almost reverses when accounting for wastages in the mobilization of resources, inflation in economy and more importantly, irregularity in financing mechanism.

Nepal's total health budget is made up of three broad sources: International aid (grants or loans from foreign funding agencies), public sector (funds raised through tax revenues and social contributions) and private sector (expenditures financed from out-of-pocket and private investments); each experiencing unpredictable behaviour in financing.

First, while historically international donor support made up almost half of the total health budget for Nepal, the last decade has seen a significant reduction in such foreign aid, with trends showing a dip down to just 5-7\% of total health expenditure for 2008-2010, blaming Nepal's inadequacy in financial management as the reason behind it. ${ }^{2}$ Furthermore, such foreign aids come with its own set of influence on our health policy. In the past, largest share of donor support was used in the area of preventive services and made up for the bulk of prophylactic initiatives within our health policy, but this pattern seems to have shifted to other service facility now. These could lead to detrimental consequence in the future of Nepal if not adjusted for immediately.

Second, while the government consistently increased the health sector's budget as a share of national budget, its own contribution has been on a steady decline in recent years. The collection through taxes and non-tax revenues support its various scheme for health policy implementation. The public health sector remains plagued with poor infrastructure, insufficient budget, poor retention of its human resources in rural areas, inadequate supply of drugs, difficulty in management and accounting systems and much more. While in 1990s, public hospitals accounted for close to 70 percent of the total hospital beds and employed most of the doctors in Nepal, today, now private healthcare centres represent 80 percent of the total available hospital beds and employs over 60 percent of the total doctors in the country. The problem of public healthcare resources not managing to grow at a desired rate poses and important challenge considering 80 percent of the health care utility still falls as a burden on public sector. ${ }^{9,10}$

Third, propelled by the vast gap in the required versus available resources, notion of poor quality of care in public sector and overall long waiting time for services; private healthcare has 
gained unprecedented access into the Nepalese health market. Growing from a mere 16 private hospitals in 1990s to over 300 today, the private health sector dominates the health system of Nepal. Such sharp rise however does come at the expense of equity within the system. ${ }^{6}$ Hospitalization into private sector can lead to catastrophic out-of-pocket (OOP) expenditure for households leading to their economic impoverishment. While developed nations consider 5 percent OOP out of family's income as unaffordable, average family in Nepal incurred far higher health expenditure of about 15 percent. ${ }^{8}$ The OOP accounts for over 50 percent of total health expenditure in Nepalese health system and affects disproportionately the poorest quintile population. ${ }^{3}$ Additionally, private health centres have an innate incentive to be focused on urbanised areas, leading to high inequity of access to quality healthcare services in rural areas of Nepal. Thus while acknowledging the vital role played by the private sector in health care service delivery throughout Nepal, it should be agreed that the favourable environment for such growth should not be at the expense of existing equity.

Set against such a background of increasing demands placed on already inadequate resources, a wakeup call is required. Healthcare professionals as leaders in health thus have an important stewardship role to play for the society to ensure that policies and actions undertaken by Nepalese healthcare system leads to improvement in overall health equity. Difficult choices are inevitable and the need for making such decisions fair and explicit will continue to gain importance. Healthcare professionals thus have to become more involved with implementation of health policies in Nepal.

Since every decision made by healthcare professional, hospital administrators, managers or policy-makers are on some level economic decisions, it is important for such individuals to have some understanding of health economics. Understanding of basic economics for healthcare professionals will equip them with the knowledge to question the policies put forth by our government, identify poorly formulated opinions and draw conclusions if it will hold up to their requirement of ethical practice in the best interest of their patients.

While doctors and healthcare professionals might have a misunderstanding of what economics really has to do with their profession, and can argue that it has no place in surgery, consulting room or laboratory; what matters is not that, but the settings leading up to it. In each instance of patient care, resources are being utilized and a whole production system is under way, all with a goal of benefiting a consumer. This requires the use of limited resources to produce goods and services that patients require. How such resources are themselves produced, who chooses what is produced with them, what are the costs involved and who pays for them; all playing the ultimate role of setting up everything before a medical professional even encounters the patient. ${ }^{5}$

So although the emphasis on financing of health in Nepal highlighted here is a small context in the grand scheme of health system functioning, it tries to portray the need for healthcare professionals to understand how our systems are constrained. And how as primary decision makers within the system, healthcare professionals with the help of health economics have the ability to take decisions in the best interest of their patients while making efficient use of limited resources. It is our responsibility as healthcare professionals to combine medical expertise with economic proficiency to help actualise the overall vision of our health systems of delivering equitable, high-quality, safe, efficient, accessible and costeffective service.

\section{REFERENCES}

1. Bhandari, P., Evers,C., Gyerra-Zubiaga, D. \& Petersen, H.. A CrossSectional Study on Patient's Access to Healthcare in a Developing Nation, ProQuest Dissertations and Thesis. 2016

2. Dulal RK, Magar A, Karki SD, Khatiwada D, Hamal PK. Analysis of health sector budget of Nepal. Journal of Nepal Medical Association. 2014;52(194):811-21.

3. Gupta I, Chowdhury S. Correlates of out-of-pocket spending on health in Nepal: implications for policy. WHO South-East Asia journal of public health. 2014 Jul 1;3(3):238.

4. Ministry of Health, Nepal. Demographic and Health Survey - 2016. Kathmandu, Nepal: MOHP. 2017.

5. Musgrove P. What is the minimum a doctor should know about health economics?. Revista Brasileira de Saúde Materno Infantil. 2001 Aug;1(2):103-9. DOI: 38292001000200003.

6. Nepal, APHIN. Association of Private Health Institution of Nepal. [online] Aphinnepal.org. 2018. Available at: http://www.aphinnepal. org. [Accessed 27 Apr.2018].
7. RTI International: Healthcare Financing in Nepal. Research Triangle Park, NC, USA. 2010

8. Saito E, Gilmour S, Rahman MM, Gautam GS, Shrestha PK, Shibuya K. Catastrophic household expenditure on health in Nepal: a crosssectional survey. Bulletin of the World Health Organization. 2014 Aug 20;92:760-7. Available at: http://who.int/bulletin/volumes/ 92/10/ 13-126615.pdf.

9. Sharma, S. Health for All: Accelerating Universal healthcare Coverage in Nepal. New Business Age. 2017. [online] Available at: http://newbusinessage.com/MagazineArticles/view/1997. [Accessed 28.04.2018]

10. World Health Organization (2007). Health Systems in Nepal: Challenges and Strategic Options. New Delhi, India: WHO. ISBN 97892-9022-266-8. 